\title{
Research on Subject Teaching Knowledge with Information Technology Deconstruction Perspective
}

\author{
Rurui Zhou \\ Office of Educational Administration, Yangtze University, Jingzhou, China \\ Email:68681700@qq.com
}

How to cite this paper: Zhou, R. R. (2019). Research on Subject Teaching Knowledge with Information Technology Deconstruction Perspective. Creative Education, 10, 1904-1913.

https://doi.org/10.4236/ce.2019.108137

Received: July 17, 2019

Accepted: August 18, 2019

Published: August 21, 2019

Copyright $\odot 2019$ by author(s) and Scientific Research Publishing Inc. This work is licensed under the Creative Commons Attribution International License (CC BY 4.0).

http://creativecommons.org/licenses/by/4.0/

\section{(c) (i) Open Access}

\begin{abstract}
This paper proposes the method of professional knowledge to affect all aspects of teacher education and teaching, corresponding to teachers' understanding of the curriculum and the role of textbooks. The methods also influence the choice and design of technology. Therefore, teachers should have a deep understanding of the reciprocity between this mechanism, which involves the relationship of roles that teachers need to know the existence form and basic composition of different technologies in the context of teaching and learning. Also, the subject teaching knowledge in the framework is an aggregation of content knowledge and pedagogy knowledge, in terms of the knowledge about courses, evaluations, and reports included in the subject teaching knowledge. In conclusion, we can have wisdom, flexibility, and tension to choose the appropriate teaching method for subject content, and support technology to promote the occurrence of learning and the deconstruction of intelligent behavior.
\end{abstract}

\section{Keywords}

Subject Content Knowledge, Subject Teaching Knowledge, Education Informatization, Education Big Data Mining

\section{Introduction}

Teachers' professional knowledge can affect all aspects of teacher education and teaching, such as teachers' understanding of the curriculum and the role of textbooks. Consequently, what teachers know and how to express their knowledge is critical to student learning. In the field of teaching, with the promotion of the professionalization of teachers, teachers become more and more profes- 
sionals as teaching professionals with specific fields (Koehler et al., 2017; Englund et al., 2017). Nowadays, researchers began to be keen to explore, teachers engaged in education and teaching, a highly complex what kind of knowledge is needed for the job and how the teacher can effectively use it in the classroom (Hew \& Brush, 2007; Laurillard, 2002; Koehler \& Mishra, 2009).

Due to the complexity and variability of teachers' teaching activities, we have different research angles and paths, and general knowledge about teachers. The meaning and connotation are not completely unified (Ertmer et al., 2010; Niess, 2005; Niess, 2011). At present, the academic world can be roughly divided into two types of research orientations, each of which has established different teachings. The teacher's knowledge framework and model reveal the essence of teacher knowledge from different perspectives (Mumtaz, 2000; Chai et al., 2010; Watson, 2001).

The first category is the "should" orientation of teacher knowledge classification research, from the perspective of what kind of knowledge teachers should have. The knowledge base is prepared for classification and deep description to define the uniqueness of teachers different from subject experts (Harris et al., 2009; Kennewell, 2001), including content knowledge, general pedagogical knowledge, subject teaching knowledge, curriculum knowledge, knowledge about learners, knowledge of educational goals and objectives, and knowledge of educational environment. Among them, subject teaching knowledge is recognized (Laurillard, 2002; Niess, 2011).

An understanding of changing the teaching of teachers and the learning of students is similar to the knowledge of "integration of technology and teaching", i.e., the second category that we used to say new technology can be used not only to reinforce existing teaching methods, but also to generate new teaching methods, and vice versa, used by teachers (John \& Sutherland, 2004; Dede, 2008; Ezziane, 2007). And performance knows how to judge the function and limitations of specific technologies, so as to design a reasonable teaching task or activity strategy; know how to use the use of certain technologies to conduct classroom management records, attendance, scoring and other class management tasks. It is worth noting that although there are many types of information technology tools or software, and the update is fast, most technologies are designed (Ting et al., 2013).

The paper is organized as follows: The first section is the introduction. The second section is about fusion technology. The third section addresses interdisciplinary cognitive tools and technology integration. The fourth section gives understanding from the perspective of deconstruction. The fourth section draws to a conclusion.

\section{Fusion Technology}

\subsection{Knowledge of Subject Content}

The presentation of the teacher's lecture can also be used for the group's achieve- 
ment report when the students are collaboratively learning; the blog is originally used for entertainment. Music and social interactions are now often used by teachers to write teaching reflection diaries; electronic interactive whiteboards can be used as a tool to replace blackboards. To carry out traditional teaching, we can also play its interactive performance and carry out cooperative inquiry teaching. The way of thinking, understanding and dealing with the relationship between technology and teaching.

The subject content knowledge (SCK) of fusion technology is the product of the fusion of technology and subject content. It refers to the teacher's technology. One of the most overlooked knowledge in research and practice. The reciprocal relationship between technology and content is reflected in two levels: Technology and subject knowledge have deep historical roots, and information technology has an impact on the nature and development of many subject areas. For example, simulation technology, visualization technology, digital computer and other technologies have emerged for mathematics, science, physics, art and many other studies.

The nature of the field has brought about fundamental changes. This influence is pervasive and infiltrated in various disciplines, but it is only the process of influence. Degrees and methods are different. Second, at the micro level, in the context of classroom teaching, different subject content needs to pass different skills. The means or information resources are characterized and presented. This includes universal software or resources, such as PPT presentations, flash, animation, podcast video. There are also software for the subject (such as geometric drawing board software, special teaching website), they are all possible effectively and appropriately express specific subject content in some optimal way.

Therefore, this required by teachers is the understanding and treatment of the relationship between technology and discipline at both the macro and micro levels. Teachers must not only know the important influence of new technology on the subject knowledge system, but also know which to use in the specific teaching environment. Some appropriate technology or resources to characterize specific teaching content.

\subsection{Subject Teaching Knowledge}

The subject teaching knowledge (STK) in the framework is an "alloy" of content knowledge and pedagogy knowledge. In addition, knowledge about courses, evaluations, and reports is also included in the subject teaching knowledge. The subject teaching knowledge (STK) of fusion technology is the interaction between teachers on subject content, teaching methods and technology.

It is also the most critical and valuable knowledge component of the framework, which represents this. The teacher's STK specifically includes such elements: know how to use technology to represent the concept; possess constructive. Ways to use technology teaching strategies; know what causes the difficulty 
of conceptual learning, and how to help through technical means. If it is said in the low-tech era, it is the most embodying the professional qualities of teachers, making teachers different.

The specifics of each informatization teaching are unique. Therefore, there is no universal application for every teacher, every class. The complex and interactive space of the three methods is more flexible and flexible. It is the basis for technology, teaching methods, and content. The field and its intertwined areas maintain a smooth, open and flexible understanding. Teachers must be able to rely on specific teaching situations.

\section{Interdisciplinary Cognitive Tools and Technology Integration}

It is further revealed seven cognitive tools (or thoughts) that are ubiquitous in the study of various subjects from an interdisciplinary perspective. Providing a new idea, it also gives teachers knowledge to understand the new connotation. At the same time, they provide flexibility for teachers. The idea of creative, informative instructional design: seeking interdisciplinary cognitive styles that meet the characteristics and needs of the discipline.

As an entry point for technology integration, it promotes the presentation, cognition and conceptualization of learning content. What are the knowledge components of the subject teaching knowledge? In comparison, it is found that almost all of them describe an understanding of strategy or characterization, so it can be regarded as a teaching activity combined with teaching characterization to promote students' knowledge of learning.

Among them, specific topic strategy knowledge refers to a certain effective teacher when the teacher helps students understand a specific concept. Activities and strategies that further deconstruct the knowledge of specific topic activities and the knowledge of specific topic representations. So far, deconstruction from the perspective of the subject teaching knowledge (STK) contains the content already presented:

- First, subject-specific activities (SSA) are about the unique teaching activities of the subject. Knowledge of methods and methods, such as inquiry learning in science classes, mathematical investigation methods, and first-hand information research in social sciences. Subject-specific Activities can be applied in the teaching of different subjects of the subject.

- Second, topic-specific activities (TSA) are about the specific concepts of understanding disciplines or Knowledge of the teaching activities and methods required for conceptual relationships, such as problem solving, demonstration, simulation, research, experimentation, etc. Teacher needs know how to combine specific activities with specific topics to form a theme-specific rather than a general teaching activity.

- Third, topic-specific representations (TSR) are specific aspects of the subject area. Read the knowledge of proper characterization and interpretation, in- 
cluding diagrams, examples, models, analogies, and so on. For example, teachers need to think about: how use the model to present the concept of "current" and how to use the chart to help understand the concept of "slope". In short, teachers need to master, which representations are appropriate for which concepts are understood or the subject is learned.

Subject Teaching Knowledge (STK) means to integrate the above three kinds of knowledge to promote students' learning. It is rooted in concrete The context of the subject area, the teaching activities involved are closely related to the subject content, and thus are not universal. Technical knowledge can be combined with general pedagogical knowledge, Develop a combination of subject-specific activities, specific thematic activities, and specific topical characterizations fusion technology discipline teaching knowledge. Consequently, the education big data mining processes are the following:

- First, the context of the macro level refers to the international, national, social, political, technological, economic and other aspects of the environment. The rapid development of global information technology requires continuous lifelong learning, and many international organizations are committed to the digital divide. In addition, these backgrounds are especially relevant to the informatization teaching of teachers.

- Second, the context of the middle level refers to local educational institutions. There is social, cultural, policy, organizational, and economic conditions. For example, parents, teachers, supervisors, schools. The attitudes and positions of leaders and other parties on the integration of technology and teaching have a great impact on the implementation of information-based teaching within the school.

- Third, the context of the micro level refers to the learning situation of classroom teaching. For example, the physical characteristics of the classroom, the demographic characteristics of teachers and students. Available resources for learning activities, curriculum standards, common goals and teaching beliefs established by teacher-student interactions, and so on. Teachers feel the most comfortable and autonomous context.

\subsection{The Complexity of the Concept}

The complexity of the concept is not only because it contains multiple layers, but also because it has two-way characteristics. It can be understood as a presence other than teachers and students. At the same time, teachers and students as actors are themselves part of the context. There are external factors such as the state of the community; elements of the context of the teacher, including self-efficacy, teaching beliefs, disciplines and school culture.

Subjective factors such as technical familiarity, successful expectations and values, and attitudes toward technology. The framework is conceptually deterministic (how), the principle explanation of the knowledge component relationship (what), the framework value and the use function (why). There are still some 
shortcomings, and it is necessary to constructively construct a consensus on understanding. Deeply understand the fusion relationship of different knowledge components, and reveal its connotation and characteristics.

This is a multifaceted way of thinking that combines the above some cognitive styles. Dimension means the convergence of feelings, knowledge and experience. In fact, the way students think in the learning process is not completely separated from each other. For example, the process of solving mathematical equations actually includes the perception of morphology because the body is a morphological structure.

\subsection{Application Technology Stages}

Thinking about the application of technology from the standpoint of discipline, it is also necessary to explore the letter from the perspective of supporting students' interdisciplinary transformational learning. It is a teacher understanding of subject objectives and content knowledge, and interdisciplinary cognitive style and belief, in terms of the wise design and seamless interface of the interaction of technology:

1) Perceiving: Both observation and imagination belong to perception. They are very important in the fields of art, science, mathematics, etc. Teachers can use information technology to support observation and imagination and enhance students' perceived experience in combination with specific subject requirements. For example, when teaching the concept of mathematics, teachers use the found functions website to map images and numbers of curved objects in nature. The comparison of the curve graphs in the study can eliminate the abstract understanding of the curve and help the students to perceive the mathematical phenomena in life.

2) Patterning. refers to the inner laws of things that can recognize surface chaos and the structure of reconstructing things and style. It is an important cognitive method for cultivating creativity, and it needs to be applied in many subject areas. For example, an architect should be able to identifying and creating different architectural structures, writer poets need to model the analysis and creation of various language structures, and so on. Learning ratios and percentages for conceptual comparisons and associations, students can discover different discipline concepts.

3) Abstracting. It is a kind of thinking that focuses on the characteristics of things and grasps the essence of the essence. It also has cross-study and features. Teachers often ask students to use abstract thinking to summarize a point, and technology can be flexibly integrated into it to promote the abstract thinking process of the discipline. For example, math teachers let students learn to create "mathematical poems" and share discussions in a networked environment.

4) Embodied thinking. refers to the use of physical sensory activities or mental activities of empathy. With technology, we can better develop your own thinking. For example, the interactive function of the geometry canvas software can 
help solve the performance of mathematical functions. Students simply drag the input points on the axis of the program, and the corresponding function graphics are instantly presented. The rhythm of the "feeling" function changes by the trajectory of the "see" function.

5) Modeling. A multidimensional representation of the real or simulated nature or structure of a thing. Modeling in art, science, mathematics and other fields are widely used, and information technology plays a very important role in cultivating students' modeling thinking. Students try to make a new mathematical table by trying geometric mapping. This is impossible to achieve in traditional geometry teaching. In addition, students can also model the geometry through technical modeling. The relationship is constructed in real time and dynamically.

\section{Understanding from the Perspective of Deconstruction}

From a deconstructive perspective, when a teacher knows how to choose and use the right technology to support the representation or presentation of a concept. When we have a general teaching activity in a subject, we have a teaching knowledge of fusion technology and when teachers can use certain skills coordination of specific subject teaching activities with specific subject characterization.

The learning of students, this is the embodiment of the teacher's knowledge. At this point, we can get the most streamlined from the perspective of deconstruction. The most typical connotation the teacher knows how to choose, design and use information technology to make it work with specific subjects, specific topics activities and specific topical characterizations are organically integrated. This is also the most practical and most stimulating combination of technology, content and teaching methods.

The deconstructive perspective also helps to clarify the "sliding feature", reaffirming the "source", in terms of teaching characterization to promote students' knowledge of learning. From the era of low technology to the intensive information, new technologies are constantly being updated. In the long run after repeated teaching and learning, technology can be understood and accepted by teachers, and merge with the original subject teaching knowledge. For example, the book was originally regarded as a special technical tool, and after hundreds of years the book has become functional and transparent, such as the cases in ubiquitous for the study of various subjects from an interdisciplinary perspective.

Everywhere, it is no longer a technology, but naturally becomes an essential component of the teaching knowledge of teachers. Compared with traditional teaching aids such as books, interest technology is more complicated and changeable. At this time, teachers' aggregation is more important. Most professional teachers know how to conduct frog anatomy in traditional classrooms, using scalpels and drawings.

\subsection{Characteristics under the Triple Perspective}

Interpreting the connotation from a number of different perspectives helps to 
reveal its full meaning and price more abundantly. Values provide a clearer insight into the attributes of this complex knowledge. Based on the triple perspective of connotation understanding, the author believes the characteristics mainly include fusion transformation, complex multi-aspects, dynamic hierarchy, practical generation and personal creativity. Convergence refers to the process of intersection, integration, and reorganization between different things or elements rather than simply superimposing or accumulating.

It refers to the transformation of things from disordered and fragmented states to mechanisms with new functions and structures. Researchers regard this as a discipline content knowledge and teaching knowledge are integrated, so that subject knowledge is transformed into knowledge in a form that is consistent with the purpose of teaching and easy for students to understand. Under the premise of understanding the characteristics and goals of the discipline, teachers should use information technology to achieve more ways of thinking, abstraction, modeling and other ways of thinking.

The nature is completely different. Teachers are different from biologists, historians, writers, and educational research. It is not because they have the quality and quantity of their expertise, but how they organize and use their knowledge. Again, it is the fundamental characteristic of teachers in the information age, which is different from technical experts or other subject experts. It is the professional knowledge of teachers' information teaching.

\subsection{Complex Multi-Faceted}

Compared with legal knowledge and technical knowledge, the complex multi-faceted nature of knowledge is more prominent and distinct. First of all, it contains numerous knowledge components cover almost all the core elements of effective teaching in an information environment. According to the analysis of the deconstruction perspective, it not only involves the use of technology for teaching characterization, but also requires teachers to master the use of technology to achieve diagrams, examples, models diversified characterization methods such as type, questioning, and analogy. Therefore, it is a teacher's knowledge of the subject as a whole, subject topics, information technology, teaching characterization and teaching activities. Know the comprehensive driving of integration.

\subsection{Dynamic Level for Practice Generation}

It has dynamic hierarchical characteristics in terms of the process of knowledge generation and degree of activation. First, the subject knowledge book with the body is not a static and static body of knowledge, but a continuously constructed dynamic body of knowledge. Known by technology Knowledge has the characteristics of continuous change. When the technical elements are involved in the teacher's original subject teaching knowledge, the resulting is even more.

Teachers with higher levels have a deep understanding of the thinking and 
concepts of using technology to promote subject teaching. Better teaching performance. The dynamic hierarchical division of this provides a new way to explore the cultivation of expert teachers in the context of information. From a deep perspective, expert teachers and non-expert teachers are combined in terms of subject knowledge, understanding of students and technical functions. It is difficult to form a high level for teachers who only pay attention to the application of technology and lack the knowledge of subject teaching. The training of expert teachers for information-based teaching needs to learn from the perspective of the advanced evolution from a deep perspective.

From the perspective of knowledge theory, teacher knowledge can be divided into theoretical knowledge and practical knowledge. In the teacher's knowledge system subject knowledge, pedagogy and psychology knowledge usually exist in the form of propositions and theories, usually through classroom learning and reading. It is taught by regular channels, so it is more theoretical and regular.

\section{Conclusion}

Compared with other types of teacher knowledge, it is more inclined to be individualized when teachers respond to specific teaching problems, adaptive, even innovative thinking decisions with highly flexible contextual characteristics and significant personal creativity. On the one hand, it is deeply influenced by the context of the teacher's teaching, reflecting the individual qualities of the teacher. It is believed that the context includes elements of macro and micro levels at the physical, cognitive, linguistic, social, psychological, and cultural levels. The specific characteristics of the level, multi-element, teachers and students are important variables that influence the process of teacher technology integration. Therefore, it is a kind of dependence on the situation that reflects the characteristics of the teacher's current teaching scene. As a result, it is a teacher's personalized thinking in the relationship among information technology, subject content and teaching methods.

\section{Conflicts of Interest}

The author declares no conflicts of interest regarding the publication of this paper.

\section{References}

Chai, C. S., Koh, J. H. L., \& Tsai, C. C. (2010). Facilitating Preservice Teachers' Development of Technological, Pedagogical, and Content Knowledge (TPACK). Educational Technology \& Society, 13, 63-73.

Dede, C. (2008). Theoretical Perspectives Influencing the Use of Information Technology in Teaching and Learning. In J. Voogt, \& G. Knezek (Eds.), International Handbook of Information Technology in Primary and Secondary Education (Vol. 20, pp. 43-62). Boston, MA: Springer. https://doi.org/10.1007/978-0-387-73315-9_3

Englund, C., Olofsson, A. D., \& Price, L. (2017). Teaching with Technology in Higher Education: Understanding Conceptual Change and Development in Practice. Higher 
Education Research \& Development, 36, 73-87. https://doi.org/10.1080/07294360.2016.1171300

Ertmer, P. A., \& Ottenbreit-Leftwich, A. T. (2010). Teacher Technology Change: How Knowledge, Confidence, Beliefs, and Culture Intersect. Journal of Research on Technology in Education, 42, 255-284. https://doi.org/10.1080/15391523.2010.10782551

Ezziane, Z. (2007). Information Technology Literacy: Implications on teaching and learning. Journal of Educational Technology \& Society, 10, 175-191.

Harris, J., Mishra, P., \& Koehler, M. (2009) Teachers' Technological Pedagogical Content Knowledge and Learning Activity Types: Curriculum-Based Technology Integration Reframed. Journal of Research on Technology in Education, 41, 393-416. https://doi.org/10.1080/15391523.2009.10782536

Hew, K. F., \& Brush, T. (2007). Integrating Technology into K-12 Teaching and Learning: Current Knowledge Gaps and Recommendations for Future Research. Educational Technology Research and Development, 55, 223-252. https://doi.org/10.1007/s11423-006-9022-5

John, P. D., \& Sutherland, R. (2004). Teaching and Learning with ICT: New Technology, New Pedagogy? Education, Communication \& Information, 4, 101-107. https://doi.org/10.1080/1463631042000210971

Kennewell, S. (2001). Using Affordances and Constraints to Evaluate the Use of Information and Communications Technology in Teaching and Learning. Journal of Information Technology for Teacher Education, 10, 101-116. https://doi.org/10.1080/14759390100200105

Koehler, M., \& Mishra, P. (2009). What Is Technological Pedagogical Content Knowledge (TPACK)? Contemporary Issues in Technology and Teacher Education, 9, 60-70.

Koehler, M., Spencer, G., Joshua, R., \& Sarah, K. (2017). What the Tech Is Going on with Teachers' Digital Teaching Portfolios? Using the TPACK Framework to Analyze Teachers' Technological Understanding. Journal of Technology and Teacher Education, 25, 31-59.

Laurillard, D. (2002). Rethinking University Teaching: A Conversational Framework for the Effective Use of Learning Technologies. London: Routledge. https://doi.org/10.4324/9780203160329

Mumtaz, S. (2000). Factors Affecting Teachers' Use of Information and Communications Technology: A Review of the Literature. Journal of Information Technology for Teacher Education, 9, 319-342. https://doi.org/10.1080/14759390000200096

Niess, M. L. (2005). Preparing Teachers to Teach Science and Mathematics with Technology: Developing a Technology Pedagogical Content Knowledge. Teaching and Teacher Education, 21, 509-523. https://doi.org/10.1016/j.tate.2005.03.006

Niess, M. L. (2011). Investigating TPACK: Knowledge Growth in Teaching with Technology. Journal of Educational Computing Research, 44, 299-317. https://doi.org/10.2190/EC.44.3.c

Ting, S. L., See-To, E. W. K., \& Tse, Y. K. (2013). Web Information Retrieval for Health Professionals. Journal of Medical Systems, 37, 9946. https://doi.org/10.1007/s10916-013-9946-3

Watson, D. M. (2001) Pedagogy before Technology: Re-Thinking the Relationship between ICT and Teaching. Education and Information Technologies, 6, 251-266.

https://doi.org/10.1023/A:1012976702296 